\title{
Functional Conservation of Wheat and Rice Mlo Orthologs in Defense Modulation to the Powdery Mildew Fungus
}

\author{
Candace Elliott, ${ }^{1}$ Fasong Zhou, ${ }^{1}$ Wolfgang Spielmeyer, ${ }^{2}$ Ralph Panstruga, ${ }^{3}$ and Paul Schulze-Lefert ${ }^{3}$ \\ ${ }^{1}$ The Sainsbury Laboratory, John Innes Centre, Colney Lane, NR4 7UH Norwich, United Kingdom; ${ }^{2}$ CSIRO Plant Industry, \\ GPO Box 1600, Canberra ACT 2601, Australia; ${ }^{3}$ Max-Planck-Institut für Züchtungsforschung, Department of Plant Microbe \\ Interactions, Carl-von-Linné-Weg 10, D-50829 Köln, Germany
}

Submitted 29 April 2002. Accepted 26 June 2002.

\begin{abstract}
Homologs of barley Mlo are found in syntenic positions in all three genomes of hexaploid bread wheat, Triticum aesti$v u m$, and in rice, Oryza sativa. Candidate wheat orthologs, designated TaMlo-A1, TaMlo-B1, and TaMlo-D1, encode three distinct but highly related proteins that are $88 \%$ identical to barley MLO and appear to originate from the three diploid ancestral genomes of wheat. TaMlo-B1 and the rice ortholog, $O s M l o 2$, are able to complement powdery mildew-resistant barley mlo mutants at the single-cell level. Overexpression of TaMlo-BI or barley Mlo leads to supersusceptibility to the appropriate powdery mildew formae speciales in both wild-type barley and wheat. Surprisingly, overexpression of either Mlo or TaMlo-B1 also mediates enhanced fungal development to tested inappropriate formae speciales. These results underline a regulatory role for MLO and its wheat and rice orthologs in a basal defense mechanism that can interfere with forma specialis resistance to powdery mildews.
\end{abstract}

Additional keywords: nonhost resistance, transient expression.

During the last decade, compelling evidence has been accumulated that gene orders are highly conserved between different species within the family of monocotyledonous plants, both at the genetic map and megabase levels (Devos and Gale 1997, 2000). This concept has been termed 'synteny' and predicts that related genes in two species are located in genomic regions sharing similar ancestral origin. Genes of two species residing in syntenic genomic locations are the result of speciation and can thus be envisaged as orthologs. In many cases, proteins encoded by orthologous genes are thought to have the same or very similar functions in both species, as often indicated by similar mutant phenotypes of the respective genes (Dubcovsky et al. 1998; Peng et al. 1999). Orthologous relationships can be substantiated if wild-type orthologs of a mutated gene complement the mutant phenotype when expressed in the mutant background (Maes et al. 2001; Suzuki et al. 2001).

Nonhost resistance can be defined as the resistance displayed by an entire plant species against all genetic variants of a pathogen species and thus affects the host range of a pathogen (Heath 2000). Nonhost resistance may be due to preformed or inducible defense responses, but it may also reflect lack of host compatibility or absence of effective pathogen virulence factors. In contrast, host resistance is defined as the resistance of plant genotypes within an otherwise susceptible host species

Corresponding author: Paul Schulze-Lefert; Telephone: +49-221-5062-350; Fax: +49-221-5062-353; E-mail: schlef@ mpiz-koeln.mpg.de
(Heath 2000). Grass powdery mildews (Blumeria graminis), obligate biotrophic ascomycete fungi, have a highly selective host range of single-plant genera, which forms the basis for the classification of eight known $B$. graminis formae speciales (Salmon 1905). For B. graminis f. sp. agropyron and $B$. graminis f. sp. tritici, Matsumura and Tosa (1995) discovered a rare common host, weeping lovegrass, that enabled crosses between the two forms and genetic analysis of fungal progeny. This showed that single resistance $(R)$ loci that control strainspecific resistance to the compatible forma specialis of a particular grass species can also recognize single powdery mildew avirulence (Avr) genes in other formae speciales.

Genetic analysis of barley resistance responses to the compatible $B$. graminis f. sp. hordei revealed two pathways: racespecific resistance triggered by single $R$ gene products, a subset of which requires the signaling genes Rarl and Sgt1 (Azevedo et al. 2002); and broad-spectrum powdery mildew resistance mediated by mutant alleles $(\mathrm{mlo})$ of the Mlo gene, which requires the presence of the wild-type genes Rorl and Ror2 (Freialdenhoven et al. 1996). The seven transmembrane wild-type MLO protein (Devoto et al. 1999) is thought to mediate defense suppression to $B$. graminis $\mathrm{f}$. sp. horde $i$ attack via direct $\mathrm{Ca}^{2+}$-dependent interaction with calmodulin (Kim et al. 2002b). MLO-mediated defense suppression also likely involves one or several small GTP-binding proteins of the ROP (Rho-related GTPases from plants) family (Schultheiss et al. 2002). Overexpression of Mlo in an Mlo wild-type background results in a supersusceptibility phenotype, suggesting that the homozygous wild-type Mlo gene under its own promoter is an incomplete suppressor of resistance (Kim et al. 2002b). Since mlo resistance was found to be ineffective against the barley leaf rust, stripe rust, stem rust, scald, and take-all fungal diseases (Jørgensen 1977), it is possible that only B. graminis f. sp. horde $i$ can effectively target MLO to mediate defense suppression. Conceptually, however, it is also conceivable that MLO functions as a docking molecule for successful powdery mildew pathogenesis. This is consistent with an early abortion of pathogenesis coincident with fungal penetration through the cell wall of attacked epidermal cells and by an epistatic action of mlo resistance in the presence of tested race-specific powdery mildew $R$ genes (Peterhänsel et al. 1997). MLO must also have functions unrelated to pathogenesis/disease resistance, since leaf senescence is accelerated in mlo mutants (Piffanelli et al. 2002).

No naturally occurring broad-spectrum resistance against powdery mildew attack has been demonstrated in wheat against $B$. graminis f. sp. tritici, and no mlo mutants have been detected. This may be because of the hexaploid nature of bread wheat and the likelihood that mutations may have to occur in 
all six copies of presumptive Mlo orthologs. In this study, we show that wheat harbors at least three expressed genes encoding proteins that are highly homologous to barley MLO, presumably originating from the three progenitor species of wheat. We used a transient single-cell gene expression assay to demonstrate that TaMlo-B1 and a rice homolog, OsMlo2, are functional orthologs of barley MLO. Furthermore, enhanced fungal development of both appropriate and inappropriate powdery mildew formae speciales upon overexpression of TaMlo$B 1$ or Mlo in wheat and barley suggests a conserved role of MLO in plant defense modulation.

\section{RESULTS}

Mlo homologs localize to syntenic positions

in wheat and rice.

Barley Mlo is located on the long arm of chromosome $4 \mathrm{H}$ between restriction fragment length polymorphism (RFLP) markers bAL88 and bAO11 (Büschges et al. 1997). We were interested whether wheat Mlo homologs localize to syntenic positions in the genome of hexaploid bread wheat. We performed RFLP-based mapping of wheat Mlo homologs with the international wheat mapping population derived from a cross between the hexaploid wheat cultivar Opata 85 and a synthetic wheat cultivar (discussed below). The full-length barley Mlo cDNA (Büschges et al. 1997) was used as a hybridization probe to map Mlo homologs in 57 of 114 recombinant inbred lines. By using the restriction enzyme HindIII, seven hybridizing bands were detected via Southern blot analysis, four of which were polymorphic between the parental lines (data not shown). Two of these fragments segregated as dominant markers and were mapped to separate loci on linkage groups $4 \mathrm{BL}$ and 4DL, whereas the two other bands were positioned to the corresponding locus on 5AL approximately $3.4 \mathrm{cM}$ proximal to marker Xabg366 (Fig. 1). The Mlo homologs on 5AL map within the homoeologous group 4 region that was shown to originate from $4 \mathrm{AL}$ and is supposed to be translocated in an early tetraploid ancestor of wheat (Nelson et al. 1995). The data demonstrate that, in all three genomes of wheat, Mlo homologs are present in syntenic positions to barley Mlo.

The rice OsMlo2 homolog was first identified by BLAST analysis using barley MLO as the query sequence. From a total of 12 predicted Mlo homologs identified in the rice genome (Goff et al. 2002), OsMlo2 shows the highest sequence similarity with barley Mlo. It was found to reside on P1 artificial chromosome (PAC) clone P0043E01 (GenBank accession no. AP000615), which is anchored by the presence of RFLP markers (e.g., C51476S, E3445S, S1554, and E61570S) to the end of rice chromosome 3 (Fig. 1). This region is considered to be syntenic to the part of linkage group 4 of the Triticeae that contains barley and wheat Mlo genes (Sharif Maroof et al. 1996; Van Deynze et al. 1995). In barley, genes residing immediately downstream of Mlo encode an oligosaccharyltransferase and a putative zinc finger protein (Panstruga et al. 1998). Interestingly, neither of these genes is found on the rice PAC clone harboring $O s M l o 2$, indicating that synteny between barley and rice is apparently not maintained at the microlevel in this chromosomal region.

Isolation of full-length wheat and rice Mlo cDNAs.

We screened a hexaploid wheat (Triticum aestivum) root cDNA library with a barley Mlo cDNA probe (discussed below). Two partial-length wheat cDNA clones sharing similarity to $H v M l o$ were isolated. One, designated pBS 4_1, consisted of

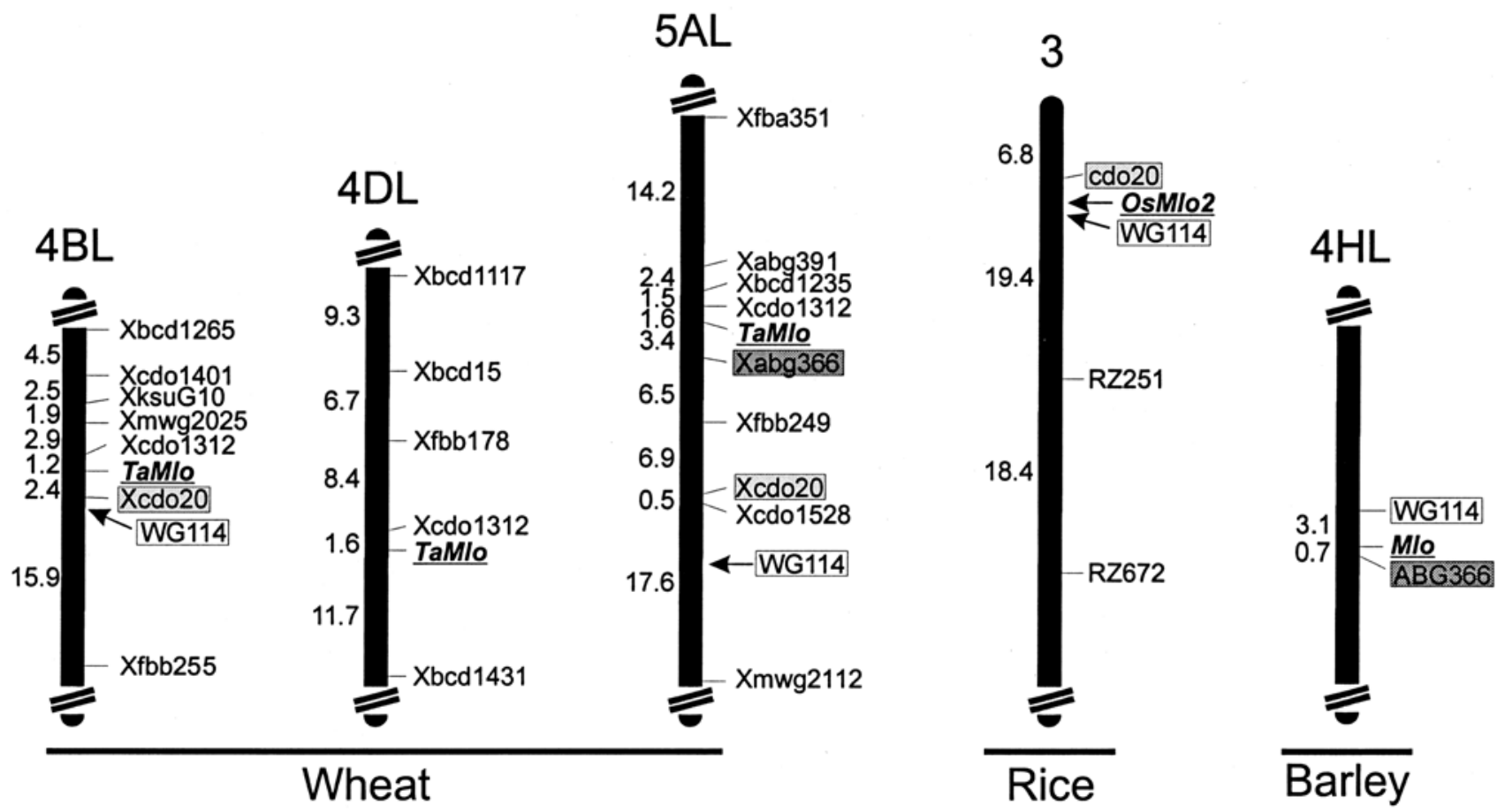

Fig. 1. Wheat and rice Mlo homologs are located in syntenic positions to barley Mlo. Schematic representation of part of the wheat linkage groups $4 \mathrm{BL}$, 4DL, and 5AL, rice chromosome 3, and barley chromosome 4HL. The positions of TaMlo homologs are indicated relative to known restriction fragment length polymorphism (RFLP) markers (discussed in text). Numbers indicate approximate genetic distances in centimorgans. Map positions of rice RFLP markers are from the Cornell RFLP 2001 map (available on-line from Gramene). Rice homolog OsMlo2 resides on P1 artificial chromosome (PAC) clone P0043E01 (GenBank accession no. AP000615 together with RFLP markers E3445S, C51476S, S1554, and E61570S that have been mapped at approximately 7.5-8 cM from the top of chromosome 3 (JRGP RFLP 2000 map; available on-line from Gramene). Positions and genetic distances of RFLP markers WG114 and ABG366 relative to barley Mlo on chromosome 4HL are taken from the work by Büschges and colleagues (1997). Approximate positions of markers WG114 on wheat 4BL, 5AL, and rice linkage group 3 are from the Synthetic/Opata 1995 and the AijiaoNante/P16 1997 RFLP maps (available on-line from Gramene). Presence of selected shared RFLP markers is highlighted by boxes in different shades of grey. 
927 base pairs (bp) of the C-terminal sequence, including a poly-A tail. The second clone, pBS 9_2, was much shorter, consisting of $376 \mathrm{bp}$ of the C-terminal sequence, including a poly-A tail. We performed 5' rapid amplification of cDNA ends (RACE) to extend DNA sequences of the two partial cDNAs toward their $5^{\prime}$ ends. This revealed the complete DNA sequence for one clone (designated TaMlo-Bl, including the putative ATG initiation codon and part of the $5^{\prime}$ untranslated region), whereas we could only partially extend the second sequence (designated TaMlo-A1; GenBank accession no. AF361933). We focused on TaMlo-Bl in subsequent work and generated oligonucleotides according to the $5^{\prime}$ and $3^{\prime}$ ends of TaMlo-B1 to reverse-transcription polymerase chain reaction (RT-PCR) amplify a continuous coding sequence for this gene (GenBank accession no. AF361932). TaMlo-B1 shares 90\% identity to barley $M l o$ at the nucleotide level, whereas the predicted encoded protein is $92 \%$ similar and $88 \%$ identical to MLO (Table 1). Two other groups independently cloned expressed wheat Mlo sequences. Salmeron and coworkers (2000) isolated three full-length wheat Mlo cDNAs (GenBank accession nos. AX063294, AX063296, and AX063298) and Yu and coworkers (L. Yu, J.-S. Niu, Z.-Q. Ma, P.-D. Chen, and D.-J. Liu, unpublished data) also cloned a wheat Mlo cDNA (GenBank accession no. AF384145). Alignment of the nucleotide sequences and predicted encoded amino acid sequences (Fig. 2A) revealed that AX063298 is almost identical to TaMlo-Al described here, whereas AX063294 and AF384145 are nearly identical to TaMlo-BI (even in their $5^{\prime}$ and $3^{\prime}$ untranslated regions). We therefore considered differences between these sequences to be cultivar-specific variations and designated AF361933 and AX063298 as TaMlo-Ala and b, respectively; AF361932, AX063294, and AF384145 as TaMlo-Bla, b, and c, respectively; and AX063296 as TaMlo-D1 (Fig. 2A). Predicted encoded proteins of all three types of wheat Mlo cDNAs share $88 \%$ identical and $92 \%$ similar amino acid residues with barley MLO (Table 1).

The high sequence similarity between TaMlo-A1, TaMlo-B1, and TaMlo-Dl suggests that these three genes represent either paralogs or homoeologous copies of the same gene originating from the A, B, and D genomes of hexaploid bread wheat. We performed RT-PCR analysis (discussed below) of diploid wheat cultivars (T. urartu, Aegilops speltoides, and A. tauschii) that are thought to represent progenitor species of hexaploid wheat (Ishii et al. 2001). A combination of oligonucleotides specific for a 404-bp internal fragment of TaMlo-Al resulted in an amplification product only for $T$. urartu, the putative ancestor of the A genome (Fig. 2B and $\mathrm{C}$ ). In addition, the sequence of the PCR product matched precisely to TaMlo-A1. In contrast, a primer combination that hybridizes to all three TaMlo sequences gave 308-bp amplification products in all cases (Fig. $2 \mathrm{~B}$ and $\mathrm{C})$. Sequence analysis of the respective amplicons revealed that the product from $A$. tauschii, the ancestor of the D genome, shared $100 \%$ identity with TaMlo-Dl. The product obtained from $A$. speltoides, a close relative of the ancestor for the B genome, was identical to TaMlo-B2. In summary, the findings suggest that TaMlo-Al and TaMlo-Dl originate from T. urartu and A. tauschii, the progenitors of the A and D genomes, respectively, whereas TaMlo-B1 derives from $A$. speltoides, a putative ancestor of the $\mathrm{B}$ genome.

Oligonucleotide primers were designed based on the genomic sequence available in GenBank to amplify the fulllength $O s M l o 2$ cDNA by RT-PCR (discussed below). We obtained a 1,740-bp product that encodes a predicted protein of 555 amino acids (plus 55 and 17 bp of the $5^{\prime}$ and $3^{\prime}$ untranslated regions, respectively). This polypeptide shares $70 \%$ identity and $79 \%$ similarity with barley MLO and the wheat orthologs described above (Table 1; Fig. 2A).

\section{Mlo orthologs complement the mlo mutant phenotype in barley.}

Transient expression of Mlo in single epidermal cells of resistant mlo mutant leaves results in restoration of susceptibility to B. graminis f. sp. hordei (Kim et al. 2002b; Shirasu et al. 1999). Thus, Mlo is able to complement mlo mutations in a cell-autonomous manner. We were interested whether the fulllength wheat and rice Mlo cDNAs (TaMlo-B1a and OsMlo2) described above were also able to restore $B$. graminis $\mathrm{f}$. $\mathrm{sp}$. hordei susceptibility to mlo leaves. We used constructs containing the respective wheat and rice genes for the cobombardment of the $G U S$-containing plasmid pUGN into mlo leaf segments (discussed below). Control transfections were performed with the reporter construct pUGN alone, with plasmid pUGLUM harboring the Mlo wild-type gene, and with pUGLU-mlo7 encoding the inactive mlo-7 mutant variant that contains a Gly ${ }^{226}$-to-Asp substitution (Shirasu et al. 1999). After pathogen challenge with $B$. graminis f. sp. hordei conidia (isolate A6), haustorium formation was assessed microscopically in transfected, GUS-stained epidermal cells as a measure of fungal penetration success. The vast majority of powdery mildew conidia were not able to penetrate cells bombarded with either GUS alone or GUS plus the mlo-7 mutant constructs (Fig. 3). In contrast, susceptibility was restored in $27 \pm$ $14 \%$ (mean \pm standard deviation) of the cells transfected with barley Mlo and GUS and in $21 \pm 13 \%$ of cells cobombarded with the TaMlo-B1 and GUS constructs. Similarly, the OsMlo2 construct was able to complement the mlo mutation, although to a lesser degree $(14 \pm 1 \%)$. Taken together, the syntenic genomic location and functional equivalence of TaMlo-BI and OsMlo2 suggest that these are orthologs of barley Mlo. This adds Mlo and its wheat and rice orthologs to a growing list of examples in which grass genes occupying syntenic positions in different grass species have been shown to maintain a conservation of function (Dubcovsky et al. 1998; Peng et al. 1999).

\section{Overexpression of TaMlo-B1 \\ confers increased susceptibility \\ to appropriate powdery mildew isolates \\ in barley and wheat.}

We recently reported that overexpression of barley Mlo in a barley Mlo wild-type genetic background renders epidermal cells supersusceptible to the barley powdery mildew fungus, $B$. graminis f. sp. hordei (Kim et al. 2002b). Since the wheat ortholog TaMlo-Bl is able to complement the mlo-5 mutant genotype with an efficiency similar to barley Mlo (discussed above; Fig. 3), we asked whether TaMlo-B1 also confers supersusceptibility to wild-type barley and wheat cultivars. After infection with their appropriate powdery mildew isolates (barley: B. graminis f. sp. hordei A6; wheat: B. graminis f. sp. tritici JIW2), we assessed penetration frequencies of barley and wheat leaves bombarded with an analogous set of constructs (GUS, mlo-7, Mlo, and TaMlo-B1). Transfection with GUS only or GUS plus mlo-7 resulted in a frequency of haustorium formation similar to the wild type in both species, whereas bombardment with barley Mlo lead to the previously observed supersusceptibility phenotype (Kim et al. 2002b) in both tested cereal species (Fig. 4A and B). Bombardment with TaMlo-B1 resulted in an increased average susceptibility in both plant species, with penetration frequencies higher than the negative

Table 1. Amino acid identity/similarity (\%) of MLO orthologs

\begin{tabular}{lcc}
\hline & TaMLOs & OsMLO \\
\hline HvMLO & $88 / 92$ & $70 / 79$ \\
TaMLOs & $\ldots$ & $70 / 79$ \\
\hline
\end{tabular}


controls (GUS and GUS plus mlo-7) but lower compared with delivery of barley Mlo (Fig. 4A and B). In conclusion, overexpression of TaMlo-Bl also enhances susceptibility to powdery mildew attack in compatible interactions with appropriate formae speciales, albeit to a lesser degree than barley Mlo.

Overexpression of Mlo or TaMlo-B1

confers supersusceptibility

to inappropriate powdery mildew isolates

in barley and wheat.

Although barley and wheat leaves are resistant to infection by $B$. graminis f. sp. tritici and B. graminis f. sp. hordei, respectively, conidia of the inappropriate forma specialis normally germinate and form appressorial germ tubes and appressoria without penetrating host cells. Occasionally, a conidium successfully penetrates a host epidermal cell but terminates growth before a mature haustorium is formed, resulting in a rudimentary haustorium or haustorial initial. Depending on the host/pathogen combination, some isolates will form mature haustoria in rare cases but stop fungal development after formation of a few secondary hyphae (Hückelhoven et al. 2001; Tosa and Shishiyama 1984; and data not shown). Since we observed an enhanced susceptibility phenotype to appropriate isolates of B. graminis upon overexpression of either Mlo or TaMlo-B1 in barley and wheat (discussed above; Fig. 4A and $B$ ), we speculated that overexpression of these genes might also affect the inappropriate forma specialis infection phenotype. To test this, we biolistically introduced the same set of constructs as described above (GUS, mlo-7, Mlo, and TaMlo$B 1$ ) into barley and wheat epidermal cells and subsequently challenged the leaf segments with A6 or JIW2. This resulted in comparable frequencies of haustorium formation for the GUS

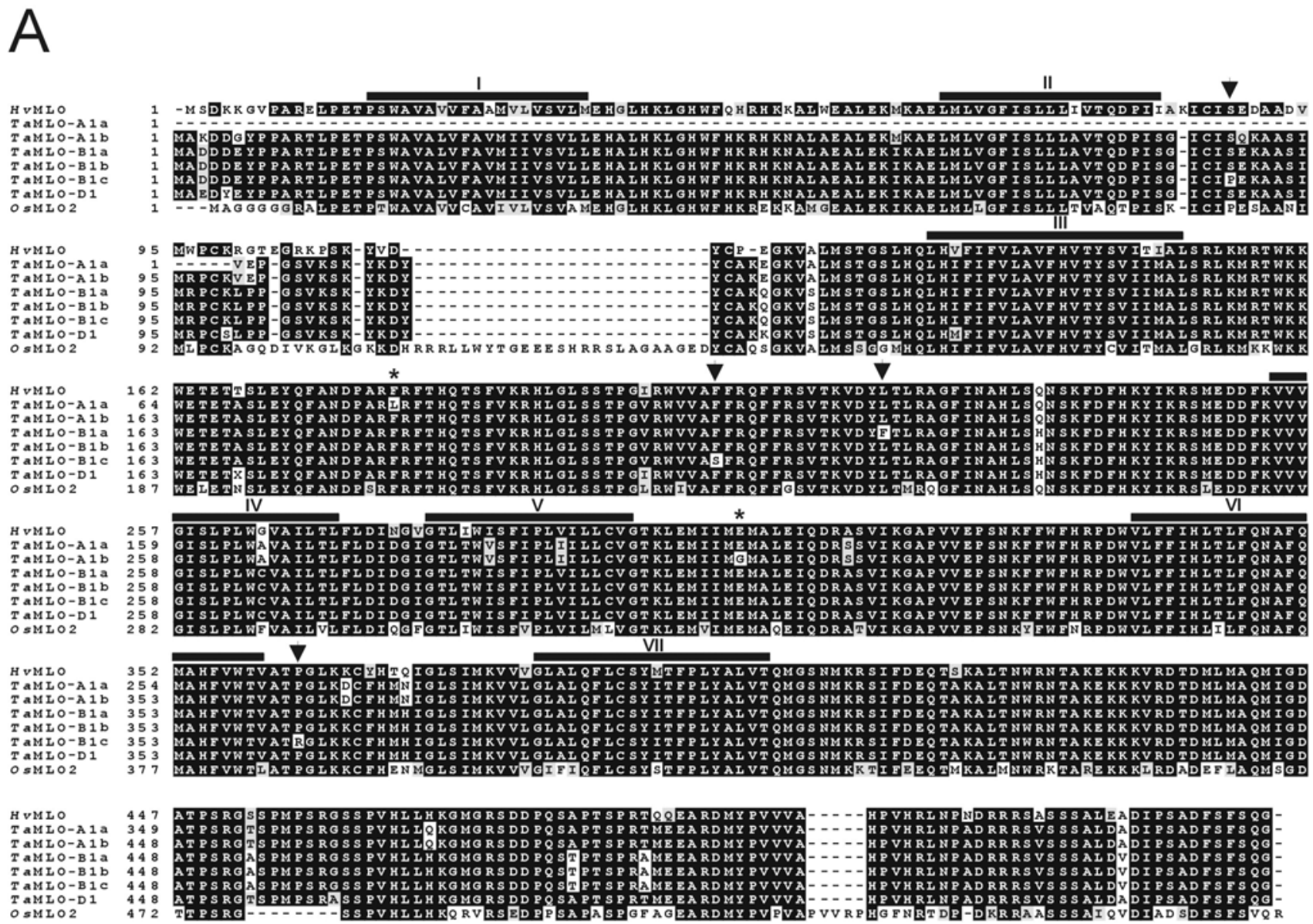

B
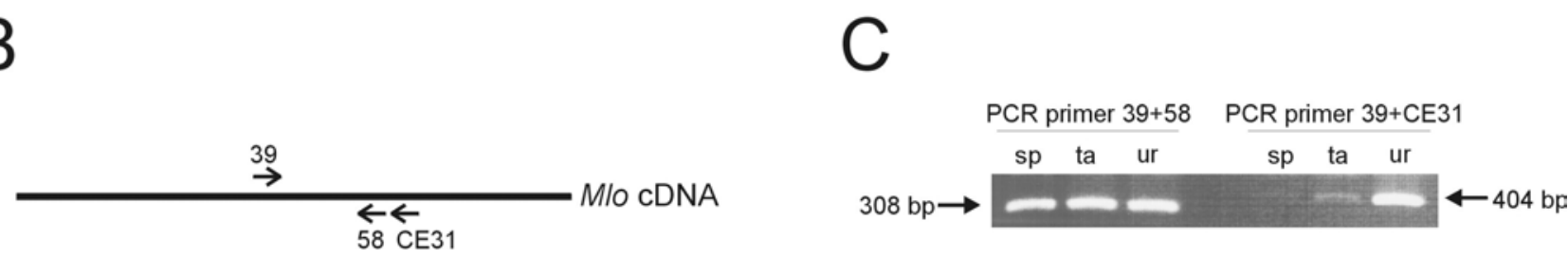

Fig. 2. Wheat Mlo homologs TaMlo-A1, TaMlo-B1, and TaMlo-D1 encode three highly related but distinct proteins. A, Amino acid sequence alignment of barley MLO (HvMLO; GenBank accession no. Z83834), wheat MLO isoforms encoded by TaMlo-Ala (GenBank accession no. AF361933), TaMlo-Alb (GenBank accession no. AX063298), TaMlo-B1a (GenBank accession no. AF361932), TaMlo-B1b (GenBank accession no. AX063294), TaMlo-B1c (GenBank accession no. AF384145), TaMlo-D1 (GenBank accession no. AX063296), and rice homolog OsMLO2 (GenBank accession no. AF384030). Approximate positions of the seven transmembrane regions (Devoto et al. 1999) are indicated by black bars above the sequences and numbered by Roman numerals. Positions of differences between TaMLO-A1a and TaMLO-A1b are indicated by an asterisk, and deviations between TaMLO-B1a, b, and c, by an arrow above the sequence. B, Schematic representation of approximate binding sites of oligonucleotide primers 39, 58, and CE31 within the Mlo cDNA. C, Reversetranscription polymerase chain reaction (RT-PCR) analysis of TaMlo transcripts from Aegilops speltoides (sp), Aegilops tauschii (ta), and Triticum urartu (ur). RT-PCR products were amplified as described in text with the given primer combinations (B) and analyzed by agarose gel electrophoresis. 
and mlo-7 control bombardments, whereas leaf segments bombarded with either barley Mlo or wheat TaMlo-B1 showed a markedly increased haustorial index (percent attacked epidermal cells containing haustoria; Fig. 5A and B). Taken together, the data indicate that overexpression of either ortholog in epidermal cells of either species leads to enhanced penetration success rates to the tested inappropriate formae speciales.

\section{DISCUSSION}

Powdery mildew-resistant barley mlo mutants were identified more than 60 years ago and have been extensively used in agriculture for more than 20 years (Jørgensen 1992). Mutants conferring a similar durable, broad-spectrum resistance phenotype have never been described for hexaploid bread wheat, $T$. aestivum. It has been tempting to speculate that this might be because of the polyploidy of wheat, resulting in multiple copies of putative wheat Mlo genes that are not amenable to mutagenic approaches. However, a molecular basis for this hypothesis has thus far been lacking. We and others have now isolated cDNA clones that are predicted to encode three distinct but highly related proteins exhibiting $88 \%$ identity to barley MLO (Table 1). Thus, T. aestivum contains at least three expressed genes that are highly homologous to barley Mlo. Similarly, Takumi and colleagues (2000) reported the cloning of three different but highly homologous wheat cDNAs representing presumptive orthologs of the barley Knox3 homeobox gene. RT-PCR analysis of putative ancestral diploid wheat cultivars suggests that each TaMlo gene originates from a different genome, representing the distinct progenitor species of bread wheat (Fig. 2B and C). Although the identity of the B genome ancestor is still controversial, our analysis supports the view that $A$. speltoides could be the donor or a close relative thereof.

RFLP-based mapping of wheat Mlo homologs places the genes in genomic positions that are syntenic to the location of barley Mlo (Fig. 1). In addition to the four polymorphic bands, wheat DNA hybridization blots identified three further bands that might represent additional genes with high homology to barley Mlo. In fact, expressed sequence tag (EST) database analysis revealed other wheat cDNA sequences with significant homology to barley Mlo. This is not unexpected, since Arabidopsis comprises 15 Mlo genes (Devoto et al., in press). In summary, the data indicate that wheat contains multiple transcribed genes encoding polypeptides with a significant sequence identity to MLO. If TaMlo-Al and TaMlo-D1 are also functionally equivalent to MLO, as shown here with TaMlo$B 1$, then this would indeed provide an explanation why no wheat mlo mutants have been identified to date. However, novel powerful biotechnological tools like double-stranded RNA interference (dsRNAi)-mediated gene silencing may facilitate the generation of $m l o$-resistant phenocopies in wheat in the near future.

Extensive areas of collinear RFLP marker order have been identified between barley and rice (and between other monocotyledonous species). However, there is still little known about the conservation of collinearity at the megabase or gene level between these two species. Dunford and colleagues (1995) showed that the order of markers present on a single rice yeast artificial chromosome (YAC) clone (and thus separated by less than $1 \mathrm{Mb}$ ) was conserved in barley. Similarly, Kilian and colleagues (1997) reported that the majority of probes derived from a rice bacterial artificial chromosome (BAC) clone syntenic to the barley Rpg locus mapped in a collinear order in barley, but they also identified markers mapping out of synteny. Analysis of a rice BAC covering the region syntenic to Rpgl revealed a highly conserved order of genes, although the Rpgl resistance gene was apparently missing in rice (Han et al. 1999). Feuillet and Keller (1999) and Dubcovsky and colleagues (2001) reported local rearrangements including single-gene duplication, inversion, deletion, and translocation events within regions that are collinear at the macrolevel. Apparently, yet another example of this phenomenon is the region harboring the rice OsMlo2 ortholog on chromosome 3, which was shown here at the macrolevel to be syntenic with the barley chromosomal segment harboring Mlo. While the latter is located adjacent to genes encoding an oligosaccharyltransferase and a putative ring finger protein (Panstruga et al. 1998), OsMlo2 is flanked upstream by a homolog of the human Dis3 gene (encoding a mitotic control protein) and downstream next to genes encoding a hypothetical protein of unknown function and a sugar transporter. Even the examination of sequences further away on the PAC clone (OsMlo2 resides at approximately 40 kilobases $(\mathrm{kb})$ in the $154-\mathrm{kb}$ PAC) failed to reveal genes with any similarity to the neighboring genes of barley Mlo. It remains, however, a possibility that OsMlo2 is not the true ortholog but a paralog thereof, which was generated through a local duplication event followed by deletion of the ortholog. If the putative OsMlo2 paralog has undergone substantial sequence diversification, this may explain the observed partial OsMLO2 activity in barley.

Single-cell expression of TaMlo-Bl in resistant ( $\mathrm{mlo}$ ) barley epidermal cells restores susceptibility to barley powdery mildew to an extent similar to barley Mlo, whereas the complementation efficiency of $\mathrm{OsMlo} 2$ is about $50 \%$ thereof (Fig. 3). Thus, TaMLO must contain all amino acid residues critical for MLO function in barley, while some of the sequence variation found between OsMLO2 and MLO/TaMLO must contribute to the partial activity of $O s \mathrm{MLO} 2$ in barley cells. Interestingly, two rice Mlo homologs that are distinct from OsMlo2 were completely inactive when tested in the transient barley gene expression system, although they share 85 and $78 \%$ sequence identity with OsMLO2 and 66 and $67 \%$ identity with barley MLO (Kim et al. 2002a; and data not shown). This may indicate that only orthologs but not other family members are able to substitute for barley MLO, which is consistent with the findings that mutational analysis of barley has failed to identify any other Mlo homologs with a powdery mildew resistancesuppressing activity.

The first extracellular loop and the cytoplasmic C-terminus (except a conserved calmodulin-binding domain) are highly diverged amongst MLO family members, both in sequence and length (Devoto et al., in press). However, sequences encoding the first extracellular loop in barley Mlo and its direct orthologs in other Hordeum species, as well as the three T. aestivum

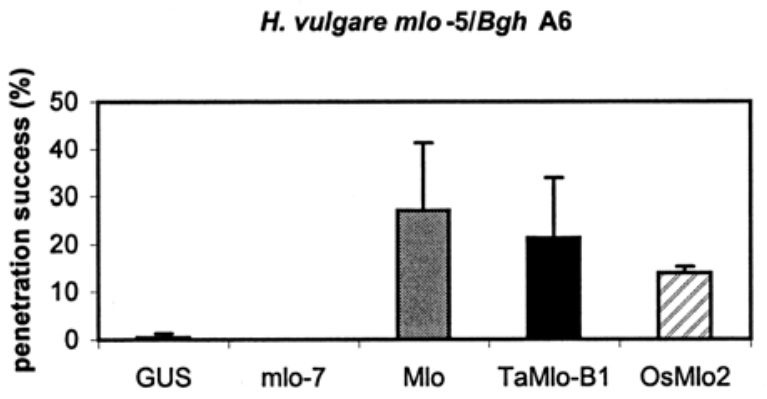

Fig. 3. TaMlo-B1 is able to complement a barley mlo mutant. Leaf segments of the resistant barley cultivar BC Ingrid mlo-5 were either bombarded with a GUS reporter plasmid or cobombarded with a GUS reporter plasmid and a construct containing either mlo-7, Mlo, TaMlo-B1, or OsMlo2. Leaves were then inoculated with Blumeria graminis f. sp. hordei A6 and stained for GUS activity and fungal structures as described in text. 
orthologs described here, have undergone purifying selection (Devoto et al., in press). It is tempting to speculate that, similar to metazoan G-protein-coupled receptors, this part of the plasma-membrane-localized protein is involved in binding isoform-specific extracellular ligands. Unlike the TaMlo ortho$\operatorname{logs}$, sequences of the first extracellular loop of the rice ortho$\log$ OsMLO2 have diverged from barley Mlo to an extent that makes it difficult to identify corresponding coding triplets, indicating absence of purifying selection. Since both wheat and rice orthologs were shown to complement barley mlo mutants, this may suggest that extracellular loop 1 is not essential for MLO defense suppression but may have a role in other processes (e.g., leaf senescence) (Piffanelli et al. 2002).

We previously reported that overexpression of Mlo in an Mlo wild-type background results in a supersusceptibility phenotype, indicating that the homozygous wild-type Mlo gene under its own promoter is an incomplete suppressor of resistance (Kim et al. 2002b). This suggests that B. graminis f. sp. hordei penetration success is either directly related to the abundance of the MLO protein or that the timing of Mlo expression is critical. Here, we have shown that overexpression of TaMlo-B1 in wild-type barley epidermal cells leads to a similar enhancedsusceptibility phenotype (Fig. 4A). Further evidence for functional similarity of TaMlo-Bl and barley Mlo results from the observation that either gene also mediates supersusceptibility in wheat (Fig. 4B) and complements resistant barley mlo mutants. However, the haustorial index was consistently higher after bombardment with barley Mlo than with wheat TaMlo-B1 in all experiments of this study (Figs. 3, 4A and B, and 5A and B).

\section{A}

\section{H. vulgare Ingrid/Bgh A6}

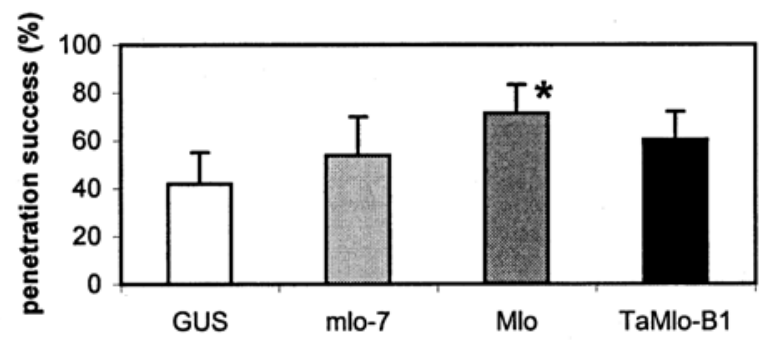

B

T. aestivum/Bgt JIW2

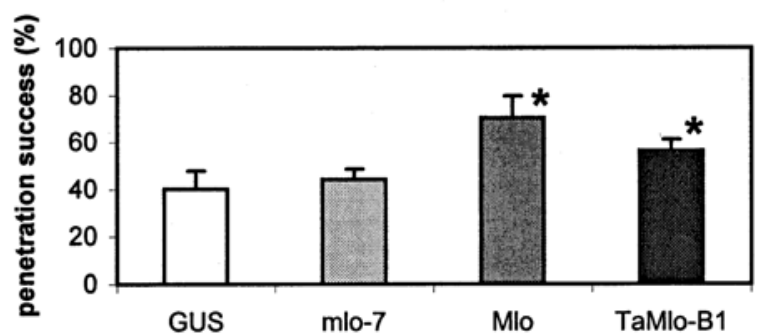

Fig. 4. Overexpression of TaMlo-B1 confers increased susceptibility to barley and wheat. Leaf segments of A, wild-type barley cultivar Ingrid or B, wheat cultivar Cerco were either bombarded with a GUS reporter plasmid or cobombarded with a GUS reporter plasmid and a construct containing either mlo-7, Mlo, or TaMlo-B1. Leaves were then inoculated either with Blumeria graminis f. sp. hordei A6 (barley) or B. graminis $\mathrm{f}$. sp. tritici JIW2 (wheat) and stained for GUS activity and fungal structures as described in text. Asterisks indicate $P<0.05$ (Student's $t$ test) compared with GUS.
We do not yet know whether this lower defense-suppression activity is a peculiarity of TaMLO-B1 or is a general feature of wheat MLO orthologs.

We demonstrated that overexpression of Mlo or TaMlo-B1 in either barley or wheat wild-type plants not only leads to an increased haustorial index to the appropriate powdery mildew formae speciales but also to increased haustorium formation against the tested inappropriate $B$. graminis f. sp. tritici/B. graminis f. sp. hordei forms (Fig. 5A and B). This implies the potential of MLO to suppress a defense response or responses in interactions involving an inappropriate forma specialis, thereby supporting the view that $B$. graminis forma specialis incompatibility is not because of a lack of virulence or absence of host-compatibility factors. Mlo gene expression under its own promoter can also modulate infection phenotypes upon challenge with an inappropriate $B$. graminis forma specialis (Peterhänsel et al. 1997). An isolate of B. graminis f. sp. tritici penetrated epidermal cell walls of a barley Mlo-susceptible line at $2.3 \%$ of interaction sites and only 1 out of $600(0.2 \%)$ inspected sites on an mlo near-isogenic line. Since this effect was dependent on Rorl and Ror2, the mechanism of MLO function in forma specialis incompatibility is likely to be similar to MLO-mediated defense suppression against the appropriate powdery mildew form. However, Hückelhoven and colleagues (2001) detected unaltered infection phenotypes on the same set of barley nonhost lines upon inoculation with a different $B$. graminis f. sp. tritici isolate. These seemingly conflicting data might be resolved by observations of Tosa and Shishiyama (1984) showing that the outcome of nonhost interactions between barley and $B$. graminis f. sp. tritici can be strongly influenced by both plant and pathogen genotype.

\section{MATERIALS AND METHODS}

\section{Plant and fungal material.}

Barley cultivars Ingrid (Mlo), mlo-5 (backcross Ingrid), and Golden Promise (Mlo), as well as the hexaploid wheat cultivar Cerco, were cultivated at $22^{\circ} \mathrm{C}$ (16-h light/8-h darkness). Diploid wheat cultivars $T$. urartu, A. speltoides, and A. tauschii were germinated on wet filter paper and grown at $22^{\circ} \mathrm{C}(16-\mathrm{h}$ light/8-h darkness). The barley powdery mildew isolate A6 and wheat powdery mildew isolate JIW2 were propagated as described (Zhou et al. 2001).

\section{Mapping of wheat homologs.}

A subset of 57 lines from the recombinant inbred mapping family developed by the International Triticeae Mapping Initiative (ITMI) and derived from a cross between the bread wheat cultivar Opata and a synthetic hexaploid (Altar84/A. tauschii) were used for RFLP mapping. The full-length barley Mlo cDNA (Büschges et al. 1997) was hybridized to genomic DNA of parental lines digested with a range of restriction enzymes to identify polymorphism. Using the restriction enzyme HindIII, RFLP markers were mapped in relation to existing framework markers with log of the likelihood ratio (LOD) scores greater than 3.0 by using the MAPMAKER program (Lander et al. 1987).

\section{Library screening.}

Bacteriophage plaques $\left(1 \times 10^{6}\right)$ of a hexaploid wheat $(T$. aestivum cv. Chinese Spring) root cDNA library were screened with a barley Mlo cDNA probe corresponding to a 1.7-kb HindIII/EcoRI fragment of pRT2E (Büschges et al. 1997) by using the following hybridization conditions: $6 \times \mathrm{SSC}(1 \times \mathrm{SSC}$ is $0.15 \mathrm{M} \mathrm{NaCl}$ plus $0.015 \mathrm{M}$ sodium citrate), $5 \times$ Denhardt's, $0.2 \%$ sodium dodecyl sulfate, and sonicated and denatured salmon sperm DNA (50 $\mu \mathrm{g} / \mathrm{ml})$ at $65^{\circ} \mathrm{C}$. This technique was used to isolate the partiallength clones for TaMlo-A1 and TaMlo-B1. 


\section{RACE.}

Total RNA was extracted from $1 \mathrm{~g}$ of flash frozen T. aestivum (cv. Bob White) primary leaves using TRI reagent (SigmaAldrich, St. Louis, MO, U.S.A.) according to the manufacturer's protocol. The resulting RNA was processed with the Oligotex mRNA purification kit (Qiagen, Valencia, CA, U.S.A.) to yield approximately $4 \mu \mathrm{g}$ of poly-A ${ }^{+}$-enriched RNA. The Marathon cDNA amplification kit (Clontech, Palo Alto, CA, U.S.A.) was used according to manufacturer's instructions to generate an oligo(dT)-primed RACE library with the above mRNA as a template. Full-length TaMlo-Bl was amplified by 35 cycles of PCR $\left(10 \mathrm{~s}\right.$ at $94^{\circ} \mathrm{C}$ and $4 \mathrm{~min}$ at $\left.68^{\circ} \mathrm{C}\right)$ using oligonucleotide primers CE62 and CE40 (Table 2).

\section{Isolation of a rice homolog cDNA.}

Total RNA was prepared from 7-day-old rice (Oryza sativa) seedling leaves (Indica variety IR64) using TRI reagent (Sigma-Aldrich). RNA was reverse transcribed using Expand reverse transcriptase (Roche, Branchburg, NJ, U.S.A.) and CE28 (Table 2), an Mlo-specific primer, according to the manufacturer's instructions. The reverse-transcribed RNA was treated with 5 units of RNaseH (Roche) for $30 \mathrm{~min}$ at $37^{\circ} \mathrm{C}$. A full-length OsMlo2 cDNA was amplified from the above template using primers KS455 and KS458 (Table 2) and Expand Hi Fidelity PCR polymerase (Roche).

\section{A}

\section{H. vulgare Golden Promise/Bgt JIW2}

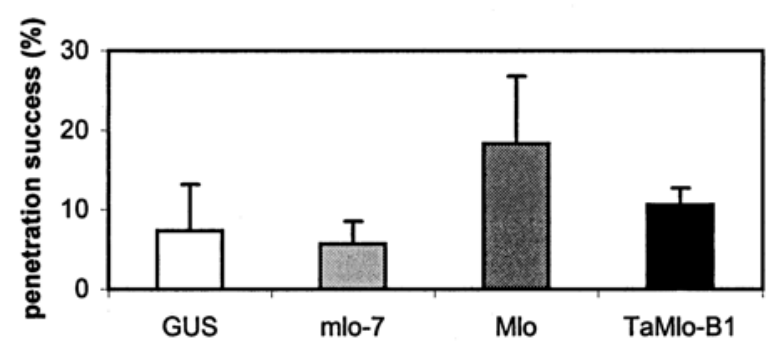

B
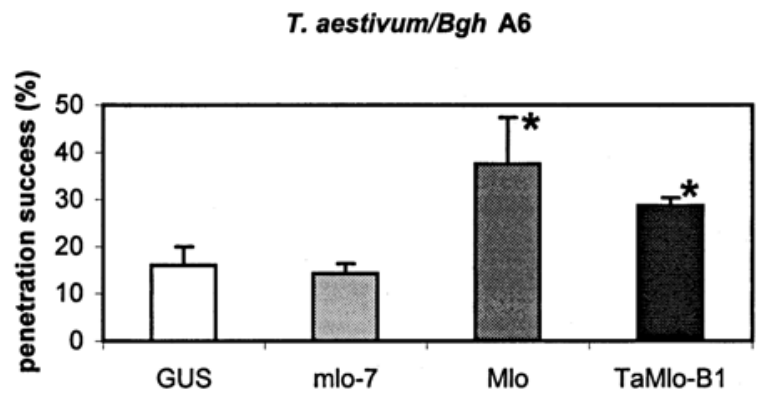

Fig. 5. Overexpression of Mlo and TaMlo-B1 confer enhanced haustorium formation of inappropriate powdery mildew formae speciales in barley and wheat. Leaf segments of A, wild-type barley cultivar Golden Promise or $\mathbf{B}$, wheat cultivar Cerco were either bombarded with a GUS reporter plasmid or cobombarded with a GUS reporter plasmid and a construct containing either $m l o-7, M l o$, or TaMlo-B1. Leaves were then inoculated with either Blumeria graminis f. sp. tritici JIW2 (barley) or $B$. graminis f. sp. hordei A6 (wheat) and stained for GUS activity and fungal structures as described in text. Note the different scales on $y$ axes in $\mathbf{A}$ and $\mathbf{B}$. Asterisks indicate $P<0.05$ (Student's $t$ test) compared with GUS.

\section{RT-PCR analysis.}

Total RNA was isolated from the leaves of three diploid cultivars of wheat (A. tauschii, A. speltoides, and T. urartu) by using the same procedures outlined above. RNA was reverse transcribed by using CE40 and Expand reverse transcriptase (Roche) according to the manufacturer's instructions. RT-PCR was performed using the Expand Hi Fidelity PCR polymerase (Roche) and either oligonucleotide primers 39 and 58 to amplify all TaMlo homologs, or primers 39 and CE31 to specifically amplify TaMlo1-A1 (Table 2 ). Thirty PCR cycles (10 s at $94^{\circ} \mathrm{C}, 45 \mathrm{~s}$ at $50^{\circ} \mathrm{C}$, and $30 \mathrm{~s}$ at $72^{\circ} \mathrm{C}$ ) were completed followed by agarose gel electrophoresis. The 308-bp fragments corresponding to amplification with primers 39 and 58, and the 404bp fragment corresponding to amplification with 39 and CE31, were extracted from the agarose gel and DNA was further purified using the Qiaquick gel extraction kit (Qiagen) before sequencing with ABI PRISM BigDye terminator cycle sequencing kit (Applied Biosystems, Foster City, CA, U.S.A.).

\section{Biolistic delivery of plasmids using the Particle Inflow Gun (PIG).}

Rice and wheat Mlo homolog cDNAs and the barley mlo cDNA variant mlo-7 (Shirasu et al. 1999) were subcloned into the Asp718 and NotI sites of the pUGLUM vector (Zhou et al. 2001) before biolistic delivery. All genes tested in this study were driven by the constitutive maize ubiquitin promoter.

DNA was precipitated onto gold particles immediately prior to bombardment as follows: $20 \mu \mathrm{l}$ of DNA (10-20 $\mu \mathrm{g}), 10 \mu \mathrm{l}$ of gold particles $(100 \mathrm{ng} / \mu \mathrm{l}), 10 \mu \mathrm{l}$ of $0.1 \mathrm{M}$ spermidine, and $25 \mu \mathrm{l}$ of $2.5 \mathrm{M} \mathrm{CaCl}_{2}$ were mixed and placed on ice. After $5 \mathrm{~min}, 45 \mu \mathrm{l}$ of the supernatant was removed, and $2 \mu \mathrm{l}$ of the resulting gold solution was used for each biolistic delivery. Three hours prior to bombardment, the apical $3.5 \mathrm{~cm}$ of the primary leaves of 5-day-old barley or wheat seedlings were cut with a sterile scalpel blade and laid adaxial side up in groups of three on a 5$\mathrm{cm}$-diameter petri dish containing $1 \%$ phytoagar and $10 \%$ sucrose. The petri dishes were opened and placed into the PIG (built by the John Innes Centre Building and Engineering Support Services according to Finer et al. [1992]) at a distance of $15 \mathrm{~cm}$ from the syringe filter and covered by a stainless steel baffle $\left(0.2-\mu \mathrm{m}\right.$ mesh). The chamber was evacuated to $0.9 \times 10^{5}$ $\mathrm{Pa}$ and $2 \mu \mathrm{l}$ of gold solution was delivered to the leaves with $5 \times$ $10^{5} \mathrm{~Pa}$ of helium. Postbombardment, the leaves were allowed to rest on the same dishes for $4 \mathrm{~h}$ before inoculation with powdery mildew spores.

\section{Fungal inoculation and microscopic examination.}

Leaf segments were placed adaxial side up in a $64-\mathrm{cm}^{2}$ rectangular dish containing $1 \%$ phytoagar and $100 \mathrm{mg}$ of benzimidazole per liter. The plastic dishes were placed inside a container covered with a layer of nylon mesh $(0.2-\mu \mathrm{m}$ pore size), and barley plants bearing freshly sporulating colonies were brushed across the mesh, allowing even distribution of single spores.

Leaf segments were vacuum-infiltrated $48-66 \mathrm{~h}$ postinoculation with GUS staining solution and incubated overnight at

Table 2. Oligonucleotide primers used in this study

\begin{tabular}{ll}
\hline Primer & \multicolumn{1}{c}{ Sequence } \\
\hline 39 & 5'-TCG ACT TCC ACA AGT ACA-3' \\
58 & 5'-GAA GAA GAG GAC CCA GTC-3' \\
CE28 & 5'-GCG GAA TTC TCA CCG TTG TGC GCT GAA-3' \\
CE31 & 5'-GAT GTT CAT ATG GAA GCA GTC C-3' \\
CE40 & 5'-TCA TCC CTG GCT GAA GGA AAA ATC TGC G-3' \\
CE62 & 5'-AAA GAG GTT GCG CTC GGG GAC CGA TG-3' \\
KS455 & 5'-CAG CGA GAG GCG TAC GTG AGT GCG T-3' \\
KS458 & 5'-GAG AAA CCT TTC GGC CAT CAC CGT TGT A-3' \\
\hline
\end{tabular}


$37^{\circ} \mathrm{C}$ according to Schweizer and colleagues (1999). Prior to observation, leaf segments were counterstained with Coomassie Brilliant Blue R 250 solution $(0.3 \%$ [wt/vol]) trichloroacetic acid and $30 \%$ [vol/vol] methanol) for $5 \mathrm{~min}$ and then rinsed twice with distilled water.

Microscopic examination of the transformed cells was used to determine the frequency with which challenge by powdery mildew resulted in cell wall penetration and fungal growth. GUS-expressing cells were inspected for the presence of an appressorium, indicating an attempted penetration by a fungal spore, or a haustorium, indicating a successful penetration event. Percent penetration success was defined as the fraction of GUS cells with a haustorium to the total number of examined GUS cells with a penetration attempt (successful or not). Data for each construct are means and standard deviation from at least three independent experiments.

\section{ACKNOWLEDGMENTS}

This work was supported by grants from the Gatsby Charitable Foundation, the Biotechnology and Biological Sciences Research Council (BBSRC), and the Max-Planck Society to C. Elliott, F. Zhou, and P. Schulze-Lefert.

\section{LITERATURE CITED}

Azevedo, C., Sadanandom, A., Kitagawa, K., Freialdenhoven, A., Shirasu, K., and Schulze-Lefert, P. 2002. The RAR1 interactor SGT1, an essential component of R gene-triggered disease resistance. Science 295: 2073-2076.

Büschges, R., Hollricher, K., Panstruga, R., Simons, G., Wolter, M., Frijters, A., van Daelen, R., van der Lee, T., Diergaarde, P., Groenendijk, J., Töpsch, S., Vos, P., Salamini, F., and Schulze-Lefert, P. 1997. The barley Mlo gene: A novel control element of plant pathogen resistance. Cell 88:695-705.

Devos, K. M., and Gale, M. D. 1997. Comparative genetics in the grasses. Plant Mol. Biol. 35:3-15.

Devos, K. M., and Gale, M. D. 2000. Genome relationships: The grass model in current research. Plant Cell 12:637-646.

Devoto, A., Piffanelli, P., Nilsson, I., Wallin, E., Panstruga, R., von Heijne, G., and Schulze-Lefert, P. 1999. Topology, subcellular localization, and sequence diversity of the Mlo family in plants. J. Biol. Chem. 274:34993-35004.

Devoto, A., Hartmann, H. A., Piffanelli, P., Elliott, C., Simmons, C., Tarmino, G., Goh, C.-S., Cohen, F. E., Emerson, B. C., Schulze-Lefert, P., and Panstruga, R. Molecular phylogeny and evolution of the plantspecific seven transmembrane MLO family. J. Mol. Evol. In press.

Dubcovsky, J., Lijavetzky, D., Appendino, L., and Tranquili, G. 1998. Comparative RFLP mapping of Triticum monococcum genes controlling vernalization requirement. Theor. Appl. Genet. 97:968-975.

Dubcovsky, J., Ramakrishna, W., SanMiguel, P. J., Busso, C. S., Yan, L. L., Shiloff, B. A., and Bennetzen, J. L. 2001. Comparative sequence analysis of colinear barley and rice bacterial artificial chromosomes. Plant Physiol. 125:1342-1353.

Dunford, R. P., Kurata, N., Laurie, D. A., Money, T. A., Minobe, Y., and Moore, G. 1995. Conservation of fine-scale DNA marker order in the genomes of rice and the Triticeae. Nucleic Acids Res. 23:2724-2728.

Feuillet, C., and Keller, B. 1999. High gene density is conserved at syntenic loci of small and large grass genomes. Proc. Natl. Acad. Sci. 96: 8265-8270.

Finer, J. J., Vain, P., Jones, M. W., and McMullen, M. D. 1992. Development of the particle inflow gun for DNA delivery to plant cells. Plant Cell Rep. 11:323-328.

Freialdenhoven, A., Peterhänsel, C., Kurth, J., Kreuzaler, F., and SchulzeLefert, P. 1996. Identification of genes required for the function of non-race-specific mlo resistance to powdery mildew in barley. Plant Cell 8:5-14.

Goff, S. A., Ricke, D., Lan, T. H., Presting, G., Wang, R. L., Dunn, M., Glazebrook, J., Sessions, A., Oeller, P., Varma, H., Hadley, D., Hutchinson, D., Martin, C., Katagiri, F., Lange, B. M., Moughamer, T., Xia, Y., Budworth, P., Zhong, J. P., Miquel, T., Paszkowski, U., Zhang, S. P., Colbert, M., Sun, W. L., Chen, L. L., Cooper, B., Park, S., Wood, T. C. Mao, L., Quail, P., Wing, R., Dean, R., Yu, Y. S., Zharkikh, A., Shen, R., Sahasrabudhe, S., Thomas, A., Cannings, R. Gutin, A., Pruss, D., Reid, J., Tavtigian, S., Mitchell, J., Eldredge, G., Scholl, T., Miller, R. M., Bhatnagar, S., Adey, N., Rubano, T., Tusneem, N., Robinson, R., Feldhaus,
J., Macalma, T., Oliphant, A., and Briggs, A. 2002. A draft sequence of the rice genome (Oryza sativa L. ssp japonica). Science 296:92-100.

Han, F., Kilian, A., Chen, J. P., Kudrna, D., Steffenson, B., Yamamoto, K., Matsumoto, T., Sasaki, T., and Kleinhofs, A. 1999. Sequence analysis of a rice BAC covering the syntenous barley Rpg1 region. Genome 42:1071-1076.

Heath, M. C. 2000. Nonhost resistance and nonspecific plant defenses. Curr. Opin. Plant Biol. 3:315-319.

Hückelhoven, R., Dechert, C., and Kogel, K.-H. 2001. Non-host resistance of barley is associated with a hydrogen peroxide burst at sites of attempted penetration by wheat powdery mildew fungus. Mol. Plant Pathol. 2:199-205.

Ishii, T., Mori, N., and Ogihara, Y. 2001. Evaluation of allelic diversity at chloroplast microsatellite loci among common wheat and its ancestral species. Theor. Appl. Genet. 103:896-904.

Jørgensen, J. H. 1977. Spectrum of resistance conferred by M1-O powdery mildew resistance genes in barley. Euphytica 26:55-62.

Jørgensen, J. H. 1992. Discovery, characterization and exploitation of Mlo powdery mildew resistance in barley. Euphytica 63:141-152.

Kilian, A., Chen, J., Han, F., Steffenson, B., and Kleinhofs, A. 1997. Towards map-based cloning of the barley stem rust resistance genes $R p g l$ and rpg 4 using rice as an intergenomic cloning vehicle. Plant Mol. Biol. 35:187-195.

Kim, M. C., Lee, S. H., Kim, J. K., Chun, H. J., Ok, H. M., Moon, B. C., Kang, C. H., Chung, W. S., Park, C. Y., Choi, M. S., Kang, Y. H., Koo, S. C., Koo, Y. C., Jung, J. C., Schulze-Lefert, P., and Cho, M. J. $2002 \mathrm{a}$. Mlo, a modulator of plant defense and cell death, is a novel calmodulin-binding protein: Isolation and characterization of a rice Mlo homologue. J. Biol. Chem. 277:19304-19314.

Kim, M. C., Panstruga, R., Elliott, C., Müller, J., Devoto, A., Yoon, H. W., Park, H., Cho, M. J., and Schulze-Lefert, P. 2002b. Calmodulin interacts with MLO to regulate defence against mildew in barley. Nature 416:447-450.

Lander, E. S., Green, P., Abrahamson, J., Barlow, A., Daly, M. J., Lincoln, S. E., and Newburg, L. 1987. MAPMAKER: An interactive computer package for constructing primary genetic linkage maps of experimental and natural populations. Genomics 1:174-181.

Maes, T., Van de Steene, N., Zethof, J., Mansour, K., D'Hauw, M., Mares, G., Van Montagu, M., and Gerats, T. 2001. Petunia Ap2-like genes and their role in flower and seed development. Plant Cell 13:229-244.

Matsumura, K., and Tosa, Y. 1995. The rye mildew fungus carries avirulence genes corresponding to wheat genes for resistance to races of the wheat mildew fungus. Phytopathology 85:753-756.

Nelson, J. C., Sorrells, M. E., Van Deynze, A. E., Lu, Y. H., Atkinson, M., Bernard, M., Leroy, P., Faris, J. D., and Anderson, J. A. 1995. Molecular mapping of wheat-Major genes and rearrangements in homoeologous groups 4, 5, and 7. Genetics 141:721-731.

Panstruga, R., Büschges, R., Piffanelli, P., and Schulze-Lefert, P. 1998. A contiguous $60 \mathrm{~kb}$ genomic stretch from barley reveals molecular evidence for gene islands in a monocot genome. Nucleic Acids Res. 26: 1056-1062.

Peng, J. R., Richards, D. E., Hartley, N. M., Murphy, G. P., Devos, K. M., Flintham, J. E., Beales, J., Fish, L. J., Worland, A. J., Pelica, F. Sudhakar, D., Christou, P., Snape, J. W., Gale, M. D., and Harberd, N. 1999. 'Green revolution' genes encode mutant gibberellin response modulators. Nature 400:256-261.

Peterhänsel, C., Freialdenhoven, A., Kurth, J., Kolsch, R., and SchulzeLefert, P. 1997. Interaction analyses of genes required for resistance responses to powdery mildew in barley reveal distinct pathways leading to leaf cell death. Plant Cell 9:1397-1409.

Piffanelli, P., Zhou, F., Casais, C., Orme, J., Schaffrath, U., Collins, N., Panstruga, R., and Schulze-Lefert, P. 2002. The barley MLO modulator of defence and cell death is responsive to biotic and abiotic stress stimuli. Plant Physiol. 129:1076-1085.

Salmeron, J. M., Weislo, L. J., Strawn, L. J., Kramer, C. M., Wang, H. X., Vernooij, B. T., Levin, J. Z., Heifetz, P. B., Patton, D. A., and Que, Q 2000. Mlo-genes controlling diseases. U.S. Patent WO 0078799-A 3.

Salmon, E. S. 1905 . On the stages of development reached by certain biologic forms of Erysiphe in cases of non-infection. New Phytol. 4:217222.

Schultheiss, H., Dechert, C., Kogel, K. H., and Hückelhoven, R. 2002. A small GTP-binding host protein is required for entry of powdery mildew fungus into epidermal cells of barley. Plant Physiol. 128:14471454 .

Schweizer, P., Pokorny, J., Abderhalden, O., and Dudler, R. 1999. A transient assay system for the functional assessment of defense-related genes in wheat. Mol. Plant-Microbe Interact. 12:647-654.

Sharif Maroof, M. A., Yang, G. P., Biyashev, R. M., Maughan, P. J., and Zhang, Q. 1996. Analysis of the barley and rice genomes by comparative RFLP linkage mapping. Theor. Appl. Genet. 92:541-551. 
Shirasu, K., Nielsen, K., Piffanelli, P., Oliver, R., and Schulze-Lefert, P. 1999. Cell-autonomous complementation of mlo resistance using a biolistic transient expression system. Plant J. 17:293-299.

Suzuki, M., Kao, C.-Y., Cocciolone, S., and McCarty, D. R. 2001. Maize VP1 complements Arabidopsis abi3 and confers a novel ABA/auxin interaction in roots. Plant J. 28:409-418.

Takumi, S., Kosugi, T., Murai, K., Mori, N., and Nakamura, C. 2000. Molecular cloning of three homeologous cDNAs encoding orthologs of the maize KNOTTED1 homeobox protein from young spikes of hexaploid wheat. Gene 249:171-181.

Tosa, Y., and Shishiyama, J. 1984. Defense reactions of barley cultivars to an inappropriate forma specialis of the powdery mildew fungus of gramineous plants. Can. J. Bot. 62:2114-2117.

Van Deynze, A. E., Nelson, J. C., Yglesias, E. S., Harrington, S. E.,
Braga, D. P., McCouch, S. R., and Sorrells, M. E. 1995. Comparative mapping in grasses-wheat relationships. Mol. Gen. Genet. 248:744754.

Zhou, F. S., Kurth, J. C., Wei, F. S., Elliott, C., Vale, G., Yahiaoui, N., Keller, B., Somerville, S., Wise, R., and Schulze-Lefert, P. 2001. Cellautonomous expression of barley Mla 1 confers race-specific resistance to the powdery mildew fungus via a Rar1-independent signaling pathway. Plant Cell 13:337-350.

\section{AUTHOR-RECOMMENDED INTERNET RESOURCE}

Gramene: A Comparative Mapping Resource for Grains (map search): http://www.gramene.org/ 